Article

\title{
Using Agile Project Management in the Design and Implementation of Activity-Based Costing Systems
}

\author{
Victor Jiménez $^{1,2, *(\mathbb{D})}$, Paulo Afonso ${ }^{2}$ (D) and Gabriela Fernandes ${ }^{3}$ (D) \\ 1 Department of Accounting and Finance, Universidad del Valle, 760043 Cali, Colombia \\ 2 ALGORITMI Center, Department of Production and Systems, University of Minho, 4710-057 Braga, Portugal; \\ psafonso@dps.uminho.pt \\ 3 CEMMPRE Center, Department of Mechanical Engineering, University of Coimbra, Rua Luís Reis Santos, \\ 3030-788 Coimbra, Portugal; gabriela.fernandes@dem.uc.pt \\ * Correspondence: victor.jimenez@correounivalle.edu.co
}

Received: 31 October 2020; Accepted: 7 December 2020; Published: 11 December 2020

check for updates

\begin{abstract}
The success of a costing system is dependent on its appropriation and assimilation by the organization. The involvement of all stakeholders from the early stages of design and implementation plays a critical role in this process. In this paper, the use of agile project management is investigated to support the design and implementation of more effective costing systems. A Design Science Research approach was followed to apply an agile project management approach —-the Scrum methodology-to the design and implementation of an Activity-Based Costing (ABC) system in a hospital imaging service. The proposed methodology identifies the roles, the events, and the most important artifacts in the design and implementation of costing systems. Research results show that applying agile project management principles contributes to a higher degree of acceptance of the costing system by the operating personnel, as well as by top management. It was also found that a simpler model (result of sprint 5), instead of a more detailed one (proposed for sprint 4), may better fit the interests of the decision makers and the organization's accounting and information systems. Thus, the best costing system is not necessarily the most complete or accurate, but the one that is most useful and adapted to the organization's needs. The definition of the product backlog, the several sprints, and the iterative process were critical in this process. The adoption of the Scrum methodology allowed the design and implementation of an ABC system more adapted to the organization's needs and allowed the early identification of problems that, traditionally, are only perceived at the end of the implementation process, therefore increasing the performance and economic sustainability of organizations.
\end{abstract}

Keywords: agile project management; Scrum methodology; project management; costing systems; activity-based costing

\section{Introduction}

The technical aspects of costing systems such as the selection of activities, cost drivers and process analysis have been widely discussed in the literature. However, in recent years, a concern that has arisen has to do with the problems related to the effective implementation of costing systems in organizations, and particularly the high failure rate of such implementations [1,2].

Anderson and Young [3] proposed three measures for the evaluation of the success of a costing system which are related to its level of accuracy, effective use and overall dimension. Accuracy is related to the improved accuracy of product costs compared to the traditional or previous costing system (which in some cases may be non-existent) [4]. The use is related to the fact that the costing system must be used for the computation and analysis of costs, and to support cost reduction and continuous improvement initiatives in the organization. The overall dimension is related to the general 
perception of stakeholders about the costing system and its relevance to support operational and strategic decision-making. Thus, the 'right' design of a costing system is fundamental for its success and effective use in the organization. Different degrees of acceptance may result from such a fit and the perception that the stakeholders have of it.

Gosselin [5,6] identified at least four phases in the design and implementation of a costing system, which are: the adoption (i.e., the decision to adopt), the design of the system, its implementation and, finally, the routinization of the practices related to the use of the costing system. In the adoption phase, the organization recognizes the need for a costing system and decides to adopt a particular one. This phase is characterized by high levels of uncertainty about the real need and relevance of the costing system. Several factors can lead to take a decision in favor of a new approach, and subsequently, its implementation, namely, pressures from several stakeholders and institutions, the need to improve management practices, or even aspects related to the product and the market. Some constraints and conditions can be important to understand the decisions made (e.g., limitations of the accounting and information systems). In the design phase, the costing system can be adapted or modified to fit better the needs and conditions of the organization. In the implementation phase, the new costing system should be introduced following an implementation plan and providing training to the collaborators. During the last phase, the routinization, the costing system is embedded in the day-to-day use of the organization [6].

Several authors have highlighted that it is vital to create an organizational culture that guarantees that once the costing system is implemented it will be effectively used as a decision-making tool $[4,7]$. For this to happen, it is essential to have the support of the organization, particularly from top managers but also from all collaborators. It is critical that the costing system and the information that is generated are aligned with the organization's strategy and that there is an appropriation and assimilation of the system by the organization. However, to be successful, all stakeholders should be involved from the design and implementation phases and not only later, at the use stage.

The use of project management concepts, approaches, tools, and techniques can increase the probability of projects' success [8-12]. Furthermore, in addition to the technical aspects of the costing system implementation, it is critical to carry out an adequate management of resources, as well as of stakeholders' expectations, for which project management practice contributes significantly [13,14].

The role of project management is to achieve goals through the development of activities supported by tried and tested tools and techniques for planning, organizing, monitoring, and control of work $[15,16]$. These activities are carried out to meet project objectives usually related to scope, time, cost, quality, risk, and benefits [8,17]. Project management is a productive ground for creative, spontaneous, and intuitive applications of particular theories, models, or methodologies to meet the established goals in a continually changing environment [18].

There are several project management standards, methodologies, methods, tools, and techniques that have been developed over the decades. They focused on technical aspects, as well as on social and human aspects. For example, the Project Management Body of Knowledge (PMBoK) standard [8], from the Project Management Institute (PMI), focused more on the technical aspects, by providing information on the processes that can be carried out for effective management, and proposes different useful tools and techniques, which need to be adapted to the particular context of each project. On the other hand, the IPMA Competence Baseline (ICB) [19], developed by the International Project Management Association (IPMA), has a particularly focus on social and human aspects, by identifying the competences of those who lead and manage a project, which are grouped in contextual, behavioral, and technical competences [20].

There are two main approaches to project management: the 'traditional' approach and the agile approach [20]. The 'traditional' approach can be applied to any project environment; however, in situations where projects involve volatility of requirements, a high degree of uncertainty of change, ambiguity, and a complex project environment, the 'traditional' approach presents difficulties in responding effectively [21]. In this scenario, an agile project management approach should be 
considered. Agile development has been proved to be adequate to dominate the presented situations and to capitalize the project changes as opportunities [22]. According to Wysocki [23], the 'traditional' approach is robust when the project is large, the goal and the solution is well-defined, and the requirements are stable. On the other hand, the agile approach is presented as an asset when the project goal is clear but the solution unclear. The design and implementation of costing system projects is characterized by complex interrelationships with a high number of interfaces, whereas 'traditional' approaches are based on linear relationships that do not reflect the full complexity of these projects [24]. In such an environment, an agile-iterative approach might contribute to the success of the design and implementation of costing system projects. Particularly, in complex organizations, with a high degree of uncertainty and different professional backgrounds, as well as with a great complexity and diversity in their information systems, which commonly are not interconnected with each other [25].

The projects are open systems dependent on the history and organizational context [26]. This paper presents and discusses the use of a methodology based on agile project management for the design and implementation of costing systems with the objective of increasing the probability of success of this type of projects. For this study, the research question is as follows: is the agile project management approach suitable and useful to design and implement effective costing systems?

Organizations need efficient and effective costing systems for supporting decision-making; using an agile project management approach, defined here as an approach able to develop a solution to a problem incrementally, can give flexibility and a high involvement of key stakeholders. Costing systems that are more effective and developed in a shorter time contribute to a higher organizational performance and economic sustainability. Organizations have shown an increase interest in incorporating sustainability into managerial concepts, both at the strategic and operational levels [27]. The linking between project management and sustainability, even if not well explored, is clear [28], as well as the costing system and economic sustainability. According to Armenia et al. [29], sustainability establishes criteria for adequate use of resources and for the evaluation of outputs in terms of economic, social, and environmental impacts. The appropriate use of accurate costing system allows for better decision-making on the exploitation of the organization's resources [30].

For the development of this study, a Design Science Research (DSR) approach was used, which makes it possible to solve a problem through an innovative way. The DSR process involves six steps: problem identification and motivation; objectives of the solution to be developed; design and development; demonstration; evaluation; and communication [31]. The problem identified is the low success rate in the design and implementation of costing systems [4,32]. The use of the Scrum methodology proposed and adapted for costing systems design and implementation used here may contribute to improve the rate of success of this type of projects, i.e., the effective use of relevant costing systems, particularly activity-based costing.

The application of the proposed methodology was carried out in the image area of a hospital where it was defined who would be the Product Owner and who will integrate the project team. The Product Owner was the person responsible for making decisions. The team responsible of implementing the costing system included medical staff, systems engineers, industrial engineers, and administrative staff. After a first meeting, the essential requirements of the costing system were established.

Once the stakeholders are identified, the product Backlog should be defined. This is a list of requirements that the costing system should meet when implemented. The requirements include, among other aspects, the identification of cost objects, processes and activities analysis, computation of the cost of the relevant cost objects (e.g., products, services), and the development of tools for decision-making based on cost information. All this is determined with the involvement of all stakeholders (i.e., medical, administrative, and operational staff), and with the support of the information systems department.

The remaining of the paper is organized as follows. Firstly, a literature review is presented, mainly focused on the implementation of costing systems and their success factors, and on agile project managements methodologies. Secondly, the proposed methodology is explained for the design and 
implementation of costing systems using the Scrum methodology, followed by the methodological aspects of the research. Thirdly, the application of the Scrum methodology in the design and implementation of a costing system is presented. Finally, the results are discussed, as well as the main conclusions and opportunities for further research.

\section{Background}

According to the PMI [8], a project "is a temporary endeavor undertaken to create a unique product, service, or result" whose value must satisfy the expected and desired needs of the stakeholders. To ensure that the project meets the needs of the stakeholders, different theories and project management approaches and methodologies have been developed, which have been redefined or adapted to be used in new economic environments, which are characterized by a high complexity and uncertainty [21]. Typically, the methodologies used can be characterized as traditional and agile methodologies; the former use a linear approach to project management [23], while the latter use an iterative, incremental, adaptive, and extreme approach.

\subsection{Costing Systems}

In Klein et al. [18], four possible approaches for costing systems are described. At the lower or simpler level is what is designated as the top-down gross costing approach, while intermediate levels include bottom-up gross costing and top-down micro costing, and bottom-up micro costing is at the higher level.

Two factors explain the fundamental differences between these approaches. First, the desired level of detail (gross costing versus micro costing), and second, the way costs are collected, which impacts in the level of cost accuracy and completeness (top-down versus bottom-up costing) [33]. From the perspective of gross costing, costs are defined at a more aggregated level (for example, costing by department). On the other hand, the micro costing is concerned with the detail of those costs (for example, the costs by product, client). From the perspective of the way costs are obtained, in the top-down approach, costs are determined from aggregate costs (typically from financial information), and in this case, the unit cost would be more like the average cost. In the bottom-up approach, costs are calculated by identifying the amount of resources used in each process, department, or service provided and accumulated successively to obtain the total costs of all cost objects.

The scenario that gives more information for decision-making is the bottom-up micro costing approach [33]. However, such a level of accuracy and detail on costs entails a large consumption of resources, and therefore, increases the costs of obtaining information. Thus, a cost-benefit analysis should be made of a more complex and sophisticated costing system. Indeed, according to Anderson and Young [3], the success of a costing system depends on not only the level of accuracy and completeness, but also on its effective use and the overall perspective that users and decision makers have about it, which are related to cultural and organizational issues [5,34].

Nevertheless, cost models have been analyzed in the literature, although in practice mainly from a technical point of view (i.e., discussing its conceptual logic and its mathematical structure to calculate costs), and if there are several examples of their effectiveness, there are also many cases of failure $[1,7,35]$. In this context, the literature rarely discusses other aspects beyond the technical aspects, neglecting the cost-benefit analysis of obtaining cost information and the effective use of such information for decision-making $[5,12,36]$.

With respect to the factors that affect the success of the design and implementation of activity-based costing systems, the literature identifies and discusses four groups of factors [5,12,37]:

- Technical factors, related to the knowledge on the concepts and procedures of an ABC system, including the identification of cost objects, activities, resources, and cost drivers, which allows to calculate the cost of the products and other relevant cost objects.

- Organizational factors, namely the support from top management, organizational structure, training, and other resources to support the implementation, organizational culture, and strategy. 
- Behavioral factors, namely those related to the perceptions, preferences, and resistance of the participants in the process of design and implementation and of the users of costing systems (e.g., resistance to change).

- Other factors, such as competence, quality, and relevance of cost information for decision-making, the size of the organization, industry characteristics, and the use of incentives for the use of the costing system and the relevance of the latter for incentives and performance systems.

Although these factors have been studied mainly in the context of $A B C$, which has been one of the most-discussed costing methodologies in recent decades $[1,2,38]$, they can be applied to the design and implementation of any costing system.

The combination of all these aspects turn the design and implementation of a costing system into a demanding and complex project. In this context, organizations should consider the use of scientific and practical knowledge on project management to carry out this process successfully. The decision might depend on the use and relevance given to the cost information, the cost of the design and implementation of the costing system and the cost of keeping it in operation. These aspects should be balanced to decide about the use of project management to guide an efficient and effective development of costing systems.

\subsection{Agile Project Management Methodologies}

The agile methodologies are inspired on the philosophies presented in the "Agile Manifesto," a proclamation created by a group of leading software practitioners responding to the growing failure of IT-related projects. It has been extended from software development to other areas that require a more agile perspective of project management $[39,40]$. The Agile Manifesto identified four principles (1) focus on individuals and interactions more than on processes and tools; (2) software in operation rather than in-depth documentation; (3) customer collaboration over contract negotiation, and (4) responding to changes more than following a plan [8].

In general, agile methods are lightweight processes that [23,39]:

- Employ short iterative cycles,

- Actively involve users to establish, prioritize, and verify requirements, and

- Rely on a team's tacit knowledge as opposed to documentation.

A truly agile methodology must be [41]:

- Iterative (take several cycles to be completed),

- Incremental (not deliver the entire product at once),

- Self-organizing (teams determine the best way to handle work), and

- Emergent (processes, principles, and work structures are recognized during the project rather than predetermined).

In agile methodologies, several planning, executing, monitoring and control, and closing project management processes are performed in each iteration. The scope of the project is divided into a set of project requirements named the product backlog. When an iteration begins, the project team must define the priorities and deliverables for the next iteration. At the end of each iteration, the product must be functional and be ready to be checked by the customer. Each iteration must increase the value and functionality of the product, which does not indicate that the product is finished at $100 \%$, but that the increments must be concluded [20,42].

Table 1 summarizes the most known agile methodologies and offers a short description of each one. 
Table 1. Agile Methodologies.

\begin{tabular}{|c|c|c|}
\hline Agile Methodology & Brief Description & References \\
\hline Scrum Methodology & $\begin{array}{l}\text { The Scrum methodology emerged from } \\
\text { technology-based companies, and it is appropriate for } \\
\text { projects with unstable requirement and for those who } \\
\text { require speed and flexibility. In the Scrum } \\
\text { methodology, some main components are typically } \\
\text { defined, namely, the product backlog, which contains a } \\
\text { wish list of all the user stories of a product, and the } \\
\text { sprint backlog, which is related to the product backlog } \\
\text { and contain a list of items that must be completed in } \\
\text { each sprint. }\end{array}$ & [43] \\
\hline Extreme Programming & $\begin{array}{l}\text { Instead analyzing and designing the entire project, } \\
\text { this methodology realizes activities throughout the } \\
\text { project in an iterative way. This methodology is based } \\
\text { on } 13 \text { principles, which are: planning game, } \\
\text { small release, metaphor, simple design, test, } \\
\text { refactoring, pair programming, continuous integration, } \\
\text { collective ownership, on site customer, } 40 \text { h weeks, } \\
\text { open workplace, and just rules. }\end{array}$ & [44] \\
\hline Lean Software Development & $\begin{array}{l}\text { Lean development is a product development } \\
\text { philosophy based on the Lean philosophy. } \\
\text { The principles of this methodology are the following: } \\
\text { create value for the customer, eliminate waste, } \\
\text { the optimization of the value stream, empowerment, } \\
\text { and continuous improvement. }\end{array}$ & [45] \\
\hline Adaptive Software Development & $\begin{array}{l}\text { The adaptive software development (ASD) is based on } \\
\text { the complex adaptive system (CAS), which assumes } \\
\text { that the adaptation of a system to its environment } \\
\text { occurs from the adaptive efforts of individuals that try } \\
\text { to improve their own benefits. ASD uses CAS } \\
\text { principles, being focused on the interaction between } \\
\text { product, stakeholders, and process. }\end{array}$ & [46] \\
\hline Crystal Methodologies & $\begin{array}{l}\text { Crystal methodologies are a group of methodologies } \\
\text { classified by color: Clear, Yellow, Orange, Red, Maroon, } \\
\text { Blue, and Violet, where the intensity of the colors is } \\
\text { associated with two key project variables, namely, } \\
\text { the need for communication and coordination within } \\
\text { the project and its level of complexity. }\end{array}$ & [47] \\
\hline
\end{tabular}

There are many typologies of projects where agile methodologies are applied [42,48]. An agile methodology frequently used is Scrum [49]. The Scrum methodology was initially identified and defined by Takeuchi and Nonaka [50], who analyzed how new products were developed in companies such as Canon, Honda, and Epson, among others. Although Takeuchi and Nonaka [50] introduced the idea of Scrum in the 1980s, it was only used as a structured methodology several years later by [43]. The Scrum methodology generates anticipated results, allows a regular management of customer expectations, brings high flexibility and adaptation to the process, mitigates risks, increases productivity and quality, aligns customer and project teams, and motivates the project team.

Scrum is a methodology widely used in software development [48,51-53]. However, its fundamentals, tools, and techniques can be used in other types of projects [54]. Scrum is an iterative methodology that assumes that the project scope is unpredictable and uncertain; thus, it should be divided into parts clearly understood and valued by stakeholders [8].

In Scrum, projects are split into cycles named sprints. A sprint represents a time box within which a set of activities must be performed. The features to be implemented in a project are kept in a list that is known as product backlog. At the beginning of each sprint, a sprint planning meeting is held, that is, 
a planning meeting in which the Product Owner prioritizes the product backlog items and the team selects the activities that it will be able to implement during the starting sprint. Tasks allocated in a sprint are transferred from the product backlog to the sprint backlog.

In a pure sprint, each day, the team makes a brief meeting (usually in the morning) called the daily Scrum. The goal of such meetings is to disseminate knowledge about what was done the previous day, identify impediments, and prioritize the work of what should be started. At the end of a sprint, the team presents the features implemented in a sprint review meeting and receives feedback. If the sprint is approved, the team goes to the next sprint and so the cycle restarts $[43,54]$.

In the Scrum methodology, all stakeholders, including customers and end users, must be continuously committed to the project and provide feedback on how deliverables work to identify if the product or service complies with their needs at each instant of time [55].

\section{Research Method}

A Design Search Research (DSR) approach was followed in this research project. Unlike traditional science research, in DSR the goals of academic research are very pragmatic. Thus, it can be used in specific projects with particular characteristics, and although generalization is not one of the strengths of this method, the results can be extrapolated to projects with similar characteristics. DSR commonly requires the creation of an artifact and/or design theory as a means to improve the current state of practice as well as existing research knowledge [56]. This methodology aims to solve recognized problems in organizations through the creation and evaluation of artifacts [57] that are grouped in four types, namely: constructs, models, methods, and instantiations [57,58].

Thus, the use of the Scrum methodology for the design and implementation of costing systems was discussed and validated through its application in an imaging service of a hospital. On average per year, the hospital performs some 270,000 outpatient consultations, covering most of the medical specialties, 150,000 admissions by the emergency department, 17,200 surgeries, and 1900 new births.

In a year, the imaging service performs over 150,000 exams, but further analysis showed that it is possible to consider homogeneous groups of exams, and 10 groups were created: Support to other services, Gastrointestinal imaging, Urologic imaging, Ultrasound, Mammography, X-ray, interventional/vascular radiology, Non contrast-enhanced MRI (magnetic resonance imaging), Contrast-enhanced MRI, Non-contrast-enhanced computed tomography and Contrast-enhanced computed tomography. The service studied performs diagnostic imaging using techniques such as $X$-radiation and ultrasounds. The exams performed in this service are mostly diagnostic in nature but are often supplemented with techniques of interventional radiology (e.g., biopsies directed by ultrasound or Computed Axial Tomography). For the development of its activities, the service has the appropriate technical equipment, namely, conventional radiology rooms, ultrasound rooms, a mammography room, and a computed tomography room. Its scope of activities extends mainly to the hospital in which it is inserted, providing support to areas of inpatient, outpatient, and emergency.

The steps of the DSR include the definition of the problem, the proposed solution, the development of the solution, the evaluation, and the communication [31,59].

- Definition of the problem: the imaging service needed to know the costs associated with the provision of its services, to identify possible opportunities for improvements and identify the better tools for supporting decision-making.

- Proposed solution: once the study object was identified, the imaging service was studied to identify some antecedents from previous studies, which resources were available for the implementation, potential limitations and future problems that could be found in the development of the project, etc. In order to carry out the diagnosis of the situation, periodic meetings were held with the project group (a person from the administration, a person in charge of the imaging service, a person in charge of the hospital's computer department, and the principal researcher). Initially, they held weekly meetings. However, as the project progressed, the periodic meetings became monthly or bi-monthly. These meetings provided a systematic collection of people's experiences, 
perceptions, and feelings within their naturalistic settings. The main objective of these meetings was to obtain different perspectives to identify the work done so far and to identify the course that the research should carry out.

- The development of the solution: after the diagnosis, the next step was to plan a series of activities that should be carried out to develop the costing system. The work was divided in several stages, and each of the tasks defined in the planning process was carried out, including the identification of cost objects, activities, resources, and the estimation of the costs of each of the cost objects. Additionally, a set of different cost centers was defined according to practice and the information systems of the hospital.

- Evaluation: an incremental approach was used to determine the appropriate costing system that fits the needs of the imaging service considering the resources which were available. Each of the deliverables went through an evaluation process made by the clinical personnel as well as the administrative personnel.

- Communication: it is performed namely through this paper, wherein the role of agile project management in the design of activity-based costing systems is discussed.

Planning, taking action, and evaluating using the Scrum methodology steps made it possible to develop the cost model, according to the existing infrastructure in the hospital and the needs of the decision makers.

For the data collection and analysis, the researcher took hand-written notes of the aspects considered in the meetings, highlighting lessons learned, activities to be carried out, and difficulties that were found in the design and implementation process of the costing system.

Data collection involved observation and participation, which provided experiential and observational access to the "world of meaning" [60,61]. Daily work routines, workshops, and meetings were observed at the organizational level. Several written field notes were prepared during the observations and informal interactions with the people involved in the process. They held more than 100 meetings.

Observation is often criticized for a potential lack of reliability [62]; however, combined with other qualitative methods, it enables the researchers to gain a better understanding of the insider's perspective [63]. Therefore, besides observation and participation, the fieldworker conducted meetings, interviews, and an analysis of the activities performed in the imaging service and of the accounting and information systems related to the object of study.

\section{Proposed Scrum Methodology for the Design and Implementation of Costing Systems}

In this paper, Scrum is proposed as an appropriate methodology to be applied in the design and implementation of costing systems. In fact, these projects must be developed incrementally, because commonly, requirements change during the project lifecycle, resulting in unpredictable challenges that cannot be planned in a predictive way.

The Scrum methodology defines three main roles in the project. The Product Owner is responsible for managing the product backlog. The Development Team works to achieve a potential increase in the value of the product at the end of each sprint. The Scrum Master is responsible for the Scrum team to adhere to Scrum principles, practices, and rules.

The definition of the project team and stakeholders can be performed in parallel with the product backlog definition. The product backlog is an ordered list of everything that might be needed in the product or service, but not necessarily all requirements of the products are placed, because the requirements can be modified over time. Once the product backlog is defined, the next stage is defining the sprint. The heart of Scrum is the sprint, a time-box of commonly one month or less, during which the value is added to the final product, which can be measured and tested by the customer. A new sprint starts immediately after the conclusion of the previous one. A sprint contains the sprint 
planning, the daily scrums, the development work, the sprint review, and the sprint retrospective [64]. Figure 1 provides a simple explanation of how the Scrum methodology works.

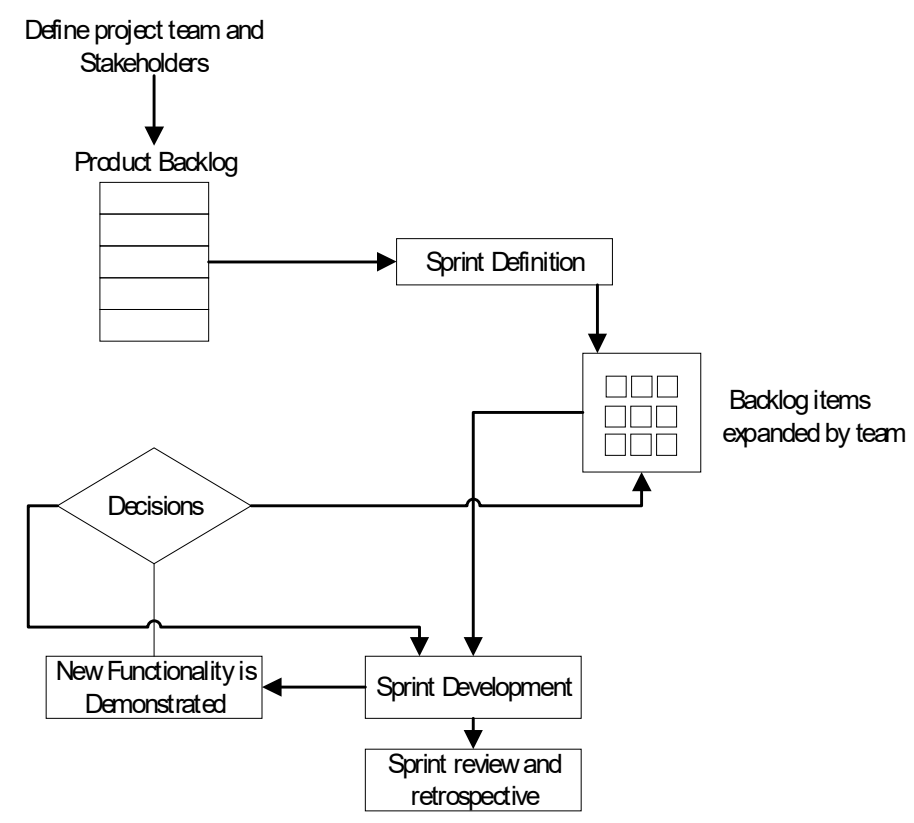

Figure 1. Scrum methodology based on Boehm and Turner [41].

The three main elements presented in the Scrum methodology are the roles, artifacts, and events. In the case of the "roles," the Scrum teams can organize themselves and perform various functions in the development of the project. In an organization, the Product Owner is responsible for ensuring that the team adds value to the business. The Product Owner represents the internal and external stakeholders, so must understand and support the needs of all users in the project, as well as the needs and functioning of the Scrum Team. If the project impacts the whole organization, this person can be someone from the top management or someone appointed by the top management. If the implementation is for a specific department or service, the Product Owner may be the director of that service or someone designated by the service who has the ability to understand how the decisions are made, how the processes are performed, and how the costing system can help to improve the decision-making process. The Scrum Master will be someone in charge of leading the project team. The project team commonly includes the operational staff, information system personnel, production managers, people from the financial area, and external staff, among others.

Scrum artifacts are those physical elements which are a result of the application of Scrum. Artifacts defined by Scrum are specifically designed to maximize transparency of key information so all stakeholders have the same understanding of the project [64]. The key artifacts are the product backlog and the sprint backlog. The product backlog includes, for example, the decision on the costing system that better suits the organization, the design of the cost models, the integration with information and software systems, etc. The sprint backlog includes a number of items that are selected successively by the Product Owner and the Development Team from the backlog product.

Scrum events allow to create regularity in the meetings and to minimize the need of unplanned meetings. Here, the rules of the game should be established, e.g., when and how the iterations between the stakeholders are realized [48].

A kick-off meeting should be conducted based on the customer's demands. In this meeting, the Product Owner creates the product backlog. The product backlog is central in the Scrum methodology. In the design and implementation of a costing system, the list includes the identification of the cost objects, the decisions that can be taken with cost information, requirements related to information systems and reporting requirements, and legislative requirements, among others. 
Once the product backlog is known, the project is divided into sprints, and sprint planning is conducted. In a costing system design, the first sprints should be related to the analysis of the initial situation to determine if there are conditions for an $A B C$ system. Namely, to analyze pros and cons of a more general costing system versus a more detailed one. Furthermore, it is necessary to identify the cost objects (e.g., products, services, clients), activities (that need to be performed to produce the cost objects), resources (e.g., labor, equipment), and cost drivers (e.g., units produced, labor hours, use of machines, and electricity consumption, among others) [48,64]. This will help not only to determine the costs but also contributes to the principle of transparency, which is one of the pillars of Scrum. In an $\mathrm{ABC}$ system, stakeholders should validate that the definition of cost objects, activities, resources, and cost drivers is correct, and the Product Owner must give its approval.

Once a sprint is identified, tools such as the burndown chart are used to plan and control the product backlog items, as well as the time and the number of resources necessary to perform the sprint. For a sprint that demands a month's work, the literature recommends $8 \mathrm{~h}$ of planning, which can vary depending on factors such as the availability of human resources, the complexity of the work, and the difficulty to collect information.

Once the sprint planning is completed, the team proceeds to execute the sprint; during its execution, no changes are allowed to the items of the sprint unless the value or scope of the items is increased, or the request of the Product Owner changes. At the end of each sprint, items that were executed are brought back to the product backlog and will be taken into account in the next sprint planning [48]. For example, if the cost of obtaining more information on the cost objects exceeds the benefits of more detailed information, one solution could be to group the cost objects (e.g., products, services) and compute the average costs. The decision on the level of detail will depend on the cost-benefit analysis associated with the detail of the information, and also on the structure necessary to determine the cost and finally on the organizational culture about costs [65]. In the design and implementation of costing systems it is expected to have several sprints. Namely, the first sprints are related to the analysis of all relevant processes, the definition of the activities, resources, and cost drivers. These are followed by the computation of costs based on algorithms that relate resources-activities-products through appropriate and available cost drivers. The next sprints can be focused on the systematize and automatization of the procedures. Finally, the conditions for the routinization of procedures and utilization of the costing system as a tool for operational and strategic decision-making can be established.

It is also necessary to define the process as each sprint will be reviewed and as adjustments can be included, when a sprint is approved and when it will be possible to proceed to the next sprint, to meet two of the three pillars of Scrum: inspection and adaptation. Other important events are related to regular meetings between team members (whose timing will depend on the size of the sprint and the availability of resources) to determine the state of sprint progress, the difficulties that have arisen in its development, and how they are or can be overcome. Other meetings are also held with the Product Owner to know the new characteristics of the product, after each sprint and to determine the project progress. Figure 2 shows a representation of these elements and how they interact, along with the design and implementation of a costing system.

In a successful costing system project, the sprints include the analysis of all relevant processes, the definition of the activities, resources, and cost drivers, the computation of costs based on algorithms that relate resources-activities-products through appropriate and available cost drivers, the systematization and automatization of the procedures, and finally, establishing the conditions for the routinization of the process.

Table 2 shows the fundamental elements of the Scrum methodology for the design and implementation of a costing system, particularly an $\mathrm{ABC}$ system. 


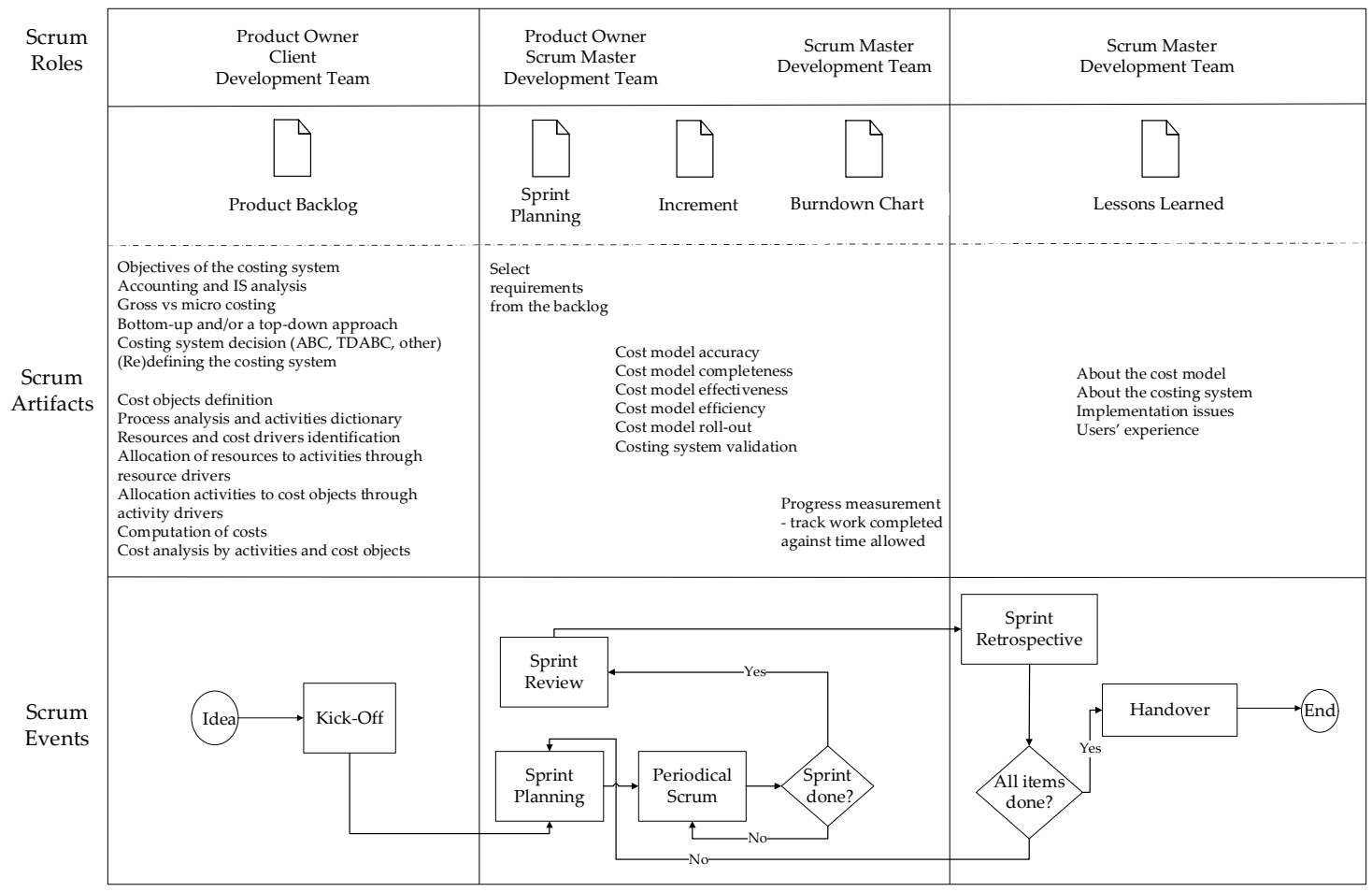

Figure 2. Scrum Methodology for the Design and Implementation of Costing Systems (based on Streule et al. [48]).

Table 2. Scrum Elements for the Design and Implementation of Costing Systems.

\begin{tabular}{ll}
\hline Stakeholders & \multicolumn{1}{c}{ Scrum Roles } \\
\hline & $\begin{array}{l}\text { Product Owner: Administrator, Director } \\
\text { Project Team: Development Team and Scrum Master } \\
\text { Users: CFO, COO, Accountants, CTO, Managers, Collaborators }\end{array}$ \\
\hline Product Backlog & \multicolumn{1}{c}{ Scrum Artifacts } \\
\hline & $\begin{array}{l}\text { A list of all requirements for the development of the costing system. For example, } \\
\text { defining the objectives of the costing system; analysis of the accounting and information } \\
\text { systems; the decision on the cost model; defining cost objects, activities, drivers, } \\
\text { resources, and all the elements of the cost model. All requirements must be listed in the } \\
\text { product backlog. In the development of the project, additional requirements can be } \\
\text { added to the product backlog, namely, the redefinition of the cost model and the } \\
\text { redefinition of the cost objects, among other aspects. }\end{array}$ \\
\hline Sprint Backlog & $\begin{array}{l}\text { Selected requirements from the backlog. The first requirements to be considered are } \\
\text { those related to the type of decisions that the costing system is going to support, } \\
\text { which defines the objectives of the system, the diagnosis of the accounting and } \\
\text { information system, and the definition of the cost model that will be developed. }\end{array}$ \\
\hline Increment & $\begin{array}{l}\text { A functional, tested, and accepted deliverable that is completed during a sprint. It is a } \\
\text { subset of the outcome of the project. In the design of a costing system, it can be focused } \\
\text { on the iterative improvements of the cost model in terms of its accuracy, completeness, } \\
\text { effectiveness, and efficiency, among other aspects. Flowcharts and spreadsheets are } \\
\text { particularly important in the context of costing systems. }\end{array}$ \\
\hline Burndown Chart & $\begin{array}{l}\text { Progress measurement is vital for the project success. It shows the project progress } \\
\text { graphically, representing the work remaining versus the time left in a timebox. }\end{array}$ \\
\hline & $\begin{array}{l}\text { Lessons learned are used to improve the project performance, avoiding repeating the } \\
\text { same mistakes. Lessons learned allow knowledge creation through reflection of the team } \\
\text { experiences and critical analysis of the factors that may have positively or negatively } \\
\text { affected the project. In this case, they are mainly related to the cost model, the costing } \\
\text { system, implementation issues, and users' experience. }\end{array}$ \\
\hline
\end{tabular}


Table 2. Cont.

\begin{tabular}{|c|c|}
\hline \multicolumn{2}{|r|}{ Scrum Events } \\
\hline Kick-off & $\begin{array}{l}\text { The first meeting that is held with the Product Owner, the Client, the Scrum Master, } \\
\text { the Team Members, and all the key stakeholders of the project. In this meeting, } \\
\text { in addition to telling what will be done with the costing system, the reason for the } \\
\text { costing system, and when the project will be carried out, the points of the product } \\
\text { backlog are prioritized and/or re-prioritized, making the corresponding estimates of the } \\
\text { effort to get work done throughout the project. }\end{array}$ \\
\hline Sprint Planning & $\begin{array}{l}\text { It should be done at the beginning of each sprint where the entire project team } \\
\text { participates. It allows the team to select the product backlog requirements to work in the } \\
\text { next sprint, to obtain an increment in the costing system. }\end{array}$ \\
\hline Sprint Review & $\begin{array}{l}\text { All members of the project team (Product Owner, Scrum Master, Development Team) } \\
\text { should participate as well as other key stakeholders. All requirements assigned in the } \\
\text { sprint are reviewed. The Product Owner analyzes them and gives their feedback, } \\
\text { and they can approve or not the sprint deliverable. The sprint reviews allow to get the } \\
\text { approval and the validation of the costing system. }\end{array}$ \\
\hline Periodical Scrum & $\begin{array}{l}\text { Short meetings where the whole team meets and each member comments on the status of } \\
\text { their tasks, focusing on the following aspects: what they did, what they have to do, } \\
\text { and which impediments they have to complete the task. The objective of these periodical } \\
\text { meetings is for the entire team to know the progress of the activities and detect } \\
\text { deviations as soon as possible. }\end{array}$ \\
\hline Sprint Retrospective & $\begin{array}{l}\text { The team learns, reflects, improves, and adapts the process. The retrospective is a time } \\
\text { for the team to learn from previous work and make small improvements. }\end{array}$ \\
\hline Handover & $\begin{array}{l}\text { The responsibility for institutionalizing the costing system is transferred to } \\
\text { the organization. }\end{array}$ \\
\hline
\end{tabular}

One of the advantages of the Scrum methodology is that when the product backlog items are verified (i.e., the identification of cost objects and the development of the cost model, among others), they must be functional. For a costing system, this is vital, because it can be the case that to obtain an additional level of detail, the marginal cost of obtaining it exceeds the benefit and the project must stop. At that moment, the costing system may already provide useful and enough information for decision-making and there is no interest to proceed with the project, as the objectives were already achieved. In other words, the project can end when the stakeholders are satisfied, or the level of detail achieved with the costing system is maximum.

\section{Demonstration and Evaluation}

Hospital costing systems are a strategic tool for operational and strategic management. However, to meet their purpose, administrative, clinical, and support staff must be involved in its design and implementation [66]. It was possible to verify, as expressed by Borges et al. [67], that services are heterogeneous and that the level of maturity of information and management systems is not the same for all. Therefore, it is recommended to prioritize the services where the costing system can be designed and implemented and then implement the solutions developed according to this prioritization.

Firstly, it was necessary to define the roles of the people involved in the project, namely the Product Owner, the Scrum Master, and the Project Team. The Product Owner was the production manager of the imaging service. The Principal Researcher played the role of Scrum Master. In this case, because of limited resources, the Scrum Master and the Product Owner were also part of the Development Team. It is not the common scheme in Scrum methodology; however, it can be presented when you have a small project team or when there are no people in the organization with knowledge of the methodology - an external person must perform these roles. The team was also composed of the director of the services and the person in charge of information systems. There was also the collaboration of the support staff (administrative staff of the service).

Once the roles of the Development Team were established, the product backlog was defined, which emphasized what the costing system should do: 
- Allow to determine the cost of each of the exams offered by the imaging service,

- Generate reports that allow the identification of relevant cost objects,

- Generate reports about inefficiencies in activities and resource utilization,

- Be computerized and automated.

Periodic meetings were scheduled first weekly, then monthly. Some difficulties arose related to the availability of the Development Team that made it difficult to hold some scheduled meetings. This happened because the team members had this project as extra work, as they had their daily activities before the project, which often forced them to cancel meetings and delay the planned work. Thus, an important lesson was learned. All stakeholders should have a specific time to work on the project, which for a public hospital can be a challenge because of the high occupancy rates and workloads they handle. Nevertheless, there was a good alignment of the Product Owner and Scrum Master within the Development Team, which was perceived as a critical factor for the success of the design and implementation of the costing system. As expected, the product backlog here raises the requirements of the costing system (the goal was clear), but leaves the way open to different solutions (solution was not clear at the beginning).

The following describes each of the seven sprints that were defined from the product backlog, how they were developed, the results obtained, and lessons learned.

\subsection{First Sprint: Diagnosis}

The first sprint aimed to achieve a diagnosis of the imaging service that allowed to determine the more adequate costing system for its context. In order to define the requirements for this diagnosis, a meeting of $4 \mathrm{~h}$ was conducted, in which a period of one month was defined, with weekly meetings, for a complete diagnosis of the problem. As a result of the diagnosis, it was found that: (1) much of the information needed for a costing system, such as recording resource consumption for each patient and activity maps, were non-existent; (2) information related to resource consumption was aggregated and found in different information systems that did not communicate with each other; and (3) cost information was relevant to identify possible inefficiencies in the process and to propose improvement projects.

\subsection{Second Sprint: Choosing the Costing Approach}

The second sprint was focused on choosing the costing methodology that would be used considering the needs of the decision makers, having a good balance between the cost of the information, the use that would be given to it, and the accuracy, completeness, and cost timeliness.

Given the conditions found in the first sprint, a bottom-up costing system was not adequate due to the lack of information and also the limitation of financial resources to create a structure that would allow costing at the micro level of each patient. Therefore, a top-down approach was adopted.

\subsection{Third Sprint: Designing a First Cost Model}

Financial information from different information systems was used to build a first version of the cost model using spreadsheets. Spreadsheets are perceived as useful and simple to use to develop a system incrementally, and therefore, a useful tool to Scrum. It is possible to start with simple models and the level of complexity increases, and accuracy depending on the needs of the organization. In addition, the spreadsheets are easy to understand by the stakeholders of the organization, which helps not only in the implementation but also in the routinization. In fact, routinization is also facilitated by the high involvement of stakeholders promoted by the Scrum methodology during the whole design and implementation process [68].

The average cost of each group of services was calculated. These two first sprints reflect the usual activities in the implementation of a costing system; however, one of the advantages of the Scrum 
methodology is that it allows constant validation by the stakeholders, which increases the engagement with the costing system and later its institutionalization.

\subsection{Fourth Sprint: Improving the Cost Model (Accuracy and Completeness)}

The fourth sprint aimed to build the algorithms used to calculate the cost of the services offered by the imaging service. Here, a difficulty emerged: all cost information was grouped in a single cost center, which means that for determining the cost of each exam, the procedure divided the full cost associated with this service by the total number of exams. Note that the total costs comprise the cost of materials, labor, and overhead costs. This method caused costs subsidiarization among services and unreliability by decision makers and medical staff of the cost information. The need was evident for a much better costing system that would allow to determine more accurate costs and to contribute to an effective cost management. Therefore, a need arose to improve the accuracy of the system, so it was necessary to create more cost centers related to the services performed. It was suggested to have from 1 to 11 cost centers related to the imaging service instead of only 1 cost center. These cost centers are: Support to other services, Gastrointestinal imaging, Urologic imaging, Ultrasound, Mammography, X-ray, interventional/vascular radiology, Non contrast-enhanced MRI (magnetic resonance imaging), Contrast-enhanced MRI, Non-contrast-enhanced computed tomography, and Contrast-enhanced computed tomography.

In a traditional approach, probably an effort would have been made to determine the cost of each of the 200 types of exams offered by the imaging service. However, this is unsustainable not only from the point of view of the cost model but would also be too much information for the decision makers, which will not be practical for real decision-making. The short sprints and the quick feedback from the users highlighted the appropriateness of a simpler cost model and shows the usefulness of Scrum methodology for the design and implementation of costing systems.

\subsection{Fifth Sprint: Simplifying the Cost Model (Effectiveness and Efficiency)}

Therefore, a fifth sprint related to the reduction of the number of cost objects was conducted. Several solutions were thought of; among them, a Pareto analysis or grouping the exams by homogeneous groups, with the latter as the chosen option. After a detailed analysis, it was possible to create homogeneous groups of exams; these groups made it possible to reduce the total number of relevant cost objects to 11 . For the determination of these costs, a weekly meeting was conducted to verify that the homogeneous groups were representative of all services offered in the imaging service.

It is worth mentioning that when using the scrum methodology, a simpler model (the result of sprint 5) was considered more appropriate for the characteristics of the service, the needs and preferences in terms of cost information, and the hospital's accounting and information systems. Instead of developing a more detailed model (sprint 4), it was possible to go back (sprint 3 ) and design a simpler model that is more appropriate to the interests of the decision makers, and which fits the existent information systems better. This generates an important practical conclusion. The best costing system is not necessarily the most complete or accurate, but the one that is most useful and adapted to the needs of the organization and that provides the best information for decision-making purposes.

\subsection{Sixth Sprint: An Activity-Based Cost Model}

The sixth sprint was centered on the design of the costing system architecture. It was designed as a structure analogous to the $\mathrm{ABC}$, where cost objects, products, and resources could be identified and related through cost drivers. Therefore, it was necessary to conduct:

- Activities identification: activities were grouped into five macro-activities, namely scheduling the patient, receiving the patient, making the exam, processing the exam, and preparing the report.

- Resources identification: resources were classified into human resources, equipment, informatics resources, materials, and others. They were identified as physicians and all the 
staff at the imaging service, eight different information systems, all the machines and equipment (e.g., scanner, ultrasonography machine, and interventional radiology) used for the realization of exams, and the clinical material used in the service delivery.

- Cost drivers' identification: cost drivers were defined as the number of exams, the direct labor hours, the number of patients, the machine hours, and the square meters.

- Cost estimation: once the cost objects were identified, namely, activities, resources, and drivers, the cost of the cost objects was computed.

One of the problems found in assigning the costs of direct materials to the final cot objects was the lack of records of materials for each exam. For example, for a Contrast-enhanced MRI, the amount of contrast depends on the type of patient (weight, health status, underlying diseases, etc.), and although there is a prescription for each patient, the hospital does not record the cost with each patient. Direct materials are allocated to the exams considering an average cost, when the consumption of resources per patient presents a high variability. A driver related to the number of exams was used for the allocation of direct materials costs, because it could not be assigned directly. In a traditional costing system, direct costs will be allocated directly; however, due to the complexity and specificity of hospitals, direct allocation is not possible, and in this case the use of drivers for the allocation of these direct costs can be a solution. This element raises an interesting discussion on costing systems, as the organization does not necessarily have to adapt to the costing system; however, the costing system must be adapted to the organization. Furthermore, costing systems are not black boxes which are merely applied-deconstruction and innovation are necessary to turn costing systems more relevant, effective, and sustainable in the organizations.

The costs computed by the new cost model and the traditional approach were compared. The latter assumes an equal cost per exam when the $\mathrm{ABC}$ cost model highlighted significant differences. These differences were obtained even when considering only the consumption of materials, as shown in Table 3.

Table 3. Cost structure of Material Costs per Exam.

\begin{tabular}{|c|c|c|c|c|c|c|c|}
\hline Type of Exam & $\begin{array}{l}\text { ABC } \\
\text { Model }\end{array}$ & $\begin{array}{c}\text { Trad. } \\
\text { Cost Model }\end{array}$ & Treat. Mat. & Med. & Electro-Medicine & Other & Total Cost \\
\hline Support to other services & 0.65 & 1.00 & $1.62 \%$ & $0.51 \%$ & $0.51 \%$ & $0.33 \%$ & $2.97 \%$ \\
\hline Gastrointestinal imaging & 0.39 & 1.00 & $0.66 \%$ & $0.87 \%$ & $0.00 \%$ & $0.01 \%$ & $1.55 \%$ \\
\hline Ultrasound & 0.01 & 1.00 & $0.01 \%$ & $0.43 \%$ & $0.10 \%$ & $0.97 \%$ & $1.51 \%$ \\
\hline Mammography & 0.18 & 1.00 & $0.00 \%$ & $0.00 \%$ & $2.49 \%$ & $0.04 \%$ & $2.53 \%$ \\
\hline X-ray & 0.01 & 1.00 & $0.06 \%$ & $0.40 \%$ & $2.58 \%$ & $4.39 \%$ & $7.43 \%$ \\
\hline Interventional/vascular radiology & 0.87 & 1.00 & $3.82 \%$ & $0.05 \%$ & $0.00 \%$ & $0.22 \%$ & $4.10 \%$ \\
\hline Contrast-enhanced MRI & 0.56 & 1.00 & $0.33 \%$ & $23.45 \%$ & $0.33 \%$ & $0.21 \%$ & $24.38 \%$ \\
\hline Non contrast-enhanced MRI & 0.02 & 1.00 & $0.001 \%$ & $0.00 \%$ & $0.01 \%$ & $0.00 \%$ & $0.02 \%$ \\
\hline Contrast-enhanced computed tomography & 0.82 & 1.00 & $0.46 \%$ & $48.17 \%$ & $0.46 \%$ & $0.30 \%$ & $49.39 \%$ \\
\hline Non contrast-enhanced computed tomography & 0.02 & 1.00 & $1.32 \%$ & $0.07 \%$ & $1.539 \%$ & $0.99 \%$ & $3.92 \%$ \\
\hline Urologic imaging & 1.00 & 1.00 & $0.37 \%$ & $1.31 \%$ & $0.00 \%$ & $0.59 \%$ & $2.27 \%$ \\
\hline Total & & & $8.67 \%$ & $75.26 \%$ & $8.02 \%$ & $8.06 \%$ & $100.00 \%$ \\
\hline
\end{tabular}

The costs by exam calculated by the ABC model were normalized as a function of the highest value, for confidentiality reasons. As can be seen, there is a huge variability in the cost of each type of exam. For example, X-Ray and Ultrasound exams consume just $1 \%$ of the materials used in Urologic imaging. The traditional costing approach is very biased, and does not reflect the real costs of the imaging service. The $A B C$ model also made it possible to identify the most expensive materials, as shown in Table 3. As evidenced, medicines and treatment materials represent about $85 \%$ of the total material costs. This information offers a new understanding of the cost structure in the imaging service and goes beyond the simple calculation of unitary costs. Its relevance for decision-making was highlighted in this specific sprint. 


\subsection{Seventh Sprint: Adding Variability}

Once the structure for cost determination was created, we proceeded to the seventh sprint, where we faced some problems. First, there were no records for the use of human resources for each service, neither administrative nor medical. Second, there were no process diagrams. Third, there is the notion of the existence of a high variability in the use of examination resources for examination; however, this variability was never measured. Some solutions for these problems arose.

First, to bring variability into the cost model, it was decided to begin to calculate the costs with materials considering the associated variability. A model that would allow to include costs' variability in these resources was built. Moreover, a study was carried out to estimate working times (considering the variability) for all homogeneous groups of exams, to allocate labor costs to the studied cost objects.

An interesting aspect that can be highlighted has to do with innovation in the traditional $A B C$ model, which is related to the importance of considering in the cost model the variability of direct costs, which is an inherent element in the provision of hospital services.

It should also be noted that the cost model developed has been considered by the Development Team as more efficient than the previous approach to measure the costs of services, since it enables the knowledge of the real costs of activities and cost objects. However, the implementation of a new costing system requires a significant financial and organizational effort, particularly for restructuring the hospital information systems.

The application of these sprints ultimately led to the determination of the cost according to the operating conditions of the imaging service. Each sprint went through a validation process by the operational and the administrative personnel associated with the services of the imaging service.

This research project changed the structure of the costing system and implied a modification in the cost information system, namely, the number of cost objects, the determination of the cost, and the identification of critical activities in the provision of the service. Cost centers associated with each of the homogeneous groups were created. In this aspect, the help of the accounting staff of the hospital was critical.

\section{Discussion}

In recent years, due to pressures from competitors and clients, organizations have been pushed to make great efforts in determining more accurately the costs of their products and services. Cost information is fundamental to support effective continuous improvement, budgeting, forecasting, and performance analysis [5,37]. A cost management system should provide information for strategic and operational purposes, namely, strategic positioning, to support negotiation processes with the funding entities, for planning, monitoring, and control of operations. In the case of hospitals, determining accurate costs is vital, since this helps in the contracting processes with the government, and serves as a control tool for compliance with the budget, which is very restricted. For that, different methodologies for estimating costs have been proposed and used. Activity-based costing $(\mathrm{ABC})$ helps to allocate costs in a logical way, and in many cases better than other costing approaches. Nevertheless, there is evidence that some organizations have had problems with its implementation, and in many cases, such implementations have not been successful $[2,7,37]$.

One of the causes of this failure is related to the fact that the focus is mostly on technical aspects and little attention is paid to the organizational aspects and the real needs of the organizations in terms of cost accounting and management [69]. Indeed, the implementation of a successful cost management system depends not only on the costing method used but also on elements related to the organizational structure (e.g., the characteristics of the available information systems) and the organizational culture (e.g., engagement, management, and cost consciousness) [37,65]. For instance, the consensus among the different stakeholders is vital, since cost management influences operational, tactical, strategic, financial, and quality issues, which are linked to all levels of management and operation in the organization $[70,71]$. In the case study presented here, the use of the Scrum methodology promoted, 
since the very beginning of the process, a high involvement of all stakeholders. Thus, medical staff was able to understand better the impact of their actions on the cost of the different exams and treatments, while administrative personnel can realize how the different activities contribute to the cost of the relevant cost objects.

Furthermore, costing systems implementation face growing challenges, which begin in the design stage. On the one hand, due to the gradual complexity of cost systems over time and the multiple skills required of a project's team to guarantee system's integrity, reliability, availability, maintenance, and security. This fosters the need for approaches that promote a higher commitment, a higher level of accountability, and a focus on results [72]. Therefore, the design and implementation of a costing system is a complex project that benefits from the use of an appropriate project management approach. This paper proposes the use of an agile project management approach, by developing a Scrum-based methodology for the design and implementation of costing systems. The cost model is particularly based on $\mathrm{ABC}$, but the general principles of the methodology proposed can be applied for other costing systems. Detailed guidance is provided for applying the methodology, through a set of clearly defined roles, events, and artifacts.

The use of the Scrum methodology for the design and implementation of costing systems highlights the importance of engagement (individual) and organizational culture (cost consciousness) for the success of the project. Particularly, in the hospital under study, the engagement of operating personnel was vital to the design and implementation process, as they were the ones who "create" information that feeds the costing system. In fact, promoting the participation of the different stakeholders, since the very beginning of the project, is the basis of the implemented Scrum methodology.

The proposed methodology is based on the use of several sprints, i.e., contributing to an iterative development process of the costing system, which allowed it to be adapted to the real needs of the imaging service of the hospital and the early identification of issues that, in a traditional approach, are mostly only perceived at the end of the implementation process. The costing approach to be adopted is a key decision taken in the first sprints. However, using the Scrum methodology, the costing system solution can be developed incrementally, allowing to identify early, for example, if a different development approach should be taken. In the case study presented here, a top-down approach was adopted, which facilitated piloting and testing, which are important tasks implicit in the Scrum methodology.

Among the difficulties of applying the proposed Scrum methodology for the design and implementation of an $\mathrm{ABC}$ system, the need of regular meetings to give and receive feedback should be highlighted. Scrum suggests daily meetings, but in practice, this was difficult to accomplish, especially when project members were working on other projects, as happened in the hospital under study. Therefore, in the proposed methodology (Figure 2), the periodicity of the periodical meetings is defined depending on the organizational context. In the development of a costing system, it is reasonable to meet with a lower periodicity, namely weekly, biweekly, or even monthly. In fact, the work can be performed with limited resources and activities, such as the identification of activities, resources, and cost objects, and their relationships can take weeks, even months, depending on the size of the organization.

Another difficulty was the limited number of available resources, namely, the Product Owner also had to participate in the Development Team. The distinction between these two roles should be clear, and when one person plays both, this sometimes leads to conflicts. This happened in the case under study, and commonly happens in other project contexts; therefore, strategies should be developed to mitigate potential conflicts between different roles. Additionally, in this case, there were no resources in the hospital that had competencies on agile project management approaches, and so, the Principal Researcher had to play the role of Scrum Master to assure the correct application of the proposed Scrum methodology. An important recommendation before applying the methodology proposed is to give training to the members involved in the project to help them to acquire key agile project management competences. 
Thus, for the effectiveness of the design and implementation of cost systems, a short-term planning is suggested focused on iteration objectives [54]. For that, the use of a product backlog artifact is proposed, which includes the costing system requirements (e.g., accounting and information systems analysis, decision on gross or micro costing, and a bottom-up and/or top-down approach), and the sprint backlog, which includes the selected requirements from the product backlog that will be responded to during each sprint. The sprint planning and sprint reviews are essential to make a lean planning of the cycle of iterations characterized by constant re-evaluations and refinements [64]. Using the agile approach, it was possible to perceive that a simpler model (result of sprint 5) was more suitable, considering the imaging service characteristics. Therefore, instead of continuing to develop a more detailed model (sprint 4), which is usually considered better, it was possible to understand that a simpler one (sprint 5) fits the existent accounting and information systems better, which it is more appropriate to the decision makers' needs, balancing the benefits and costs of the costing system.

Additionally, using a detailed list of activities with incremental and constant deliveries, as well as lean and informal documentation [64] to share among the project stakeholders, allowed to develop a costing system that responds to the different stakeholders' needs. The relevance of the proposed Scrum methodology also resulted in identifying earlier the necessary changes in the cost model. For this, the use of physical and/or virtual visual artifacts and devices was also vital, such as flowcharts, figures, and particularly, spreadsheets. In fact, spreadsheets have the advantage of being widely accepted by many organizations, since they can be easily understood and used by almost all professionals. Spreadsheets can be used for the development of simple costing systems and also for piloting and testing.

Furthermore, costing systems based on spreadsheets instead of complex software are easier to understand and to manage, particularly during the design stage. Indeed, using spreadsheets can help to open some black boxes, contributing to a higher level of acceptance by all stakeholders. This brings innovation and adaptation/re-invention opportunities to the organizational context, which are necessary to turn costing systems more accurate, effective, and efficient. The piloting and testing that are fundamental in the Scrum methodology helped in this project to promote awareness among the key stakeholders. All this asks for incremental developments, and therefore, for the Scrum methodology $[73,74]$ to use short and frequent team meetings and multidisciplinary teams, self-managed and with low project hierarchy [64].

Finally, the vital sustainability principles can be integrated in agile project management approaches, such as the SCRUM methodology here proposed for the design and implementation of costing systems. According to Silvius et al. [75], it is possible to integrate the six sustainability principles: (1) balancing or harmonizing social, environmental, and economic interests; (2) short-term and long-term orientation; (3) local and global orientation; (4) consuming income, not capital; (5) transparency and accountability; and (6) personal values and ethics. In addition, the traditional five project management groups of processes from PMBOK can be integrated [8]: initiating, planning, executing, monitoring, and closing. In the initiating and planning processes group, sustainability principles are integrated into the objectives and scope of projects. The executing and monitoring processes group enables the integration of sustainability principles into the process of creating project outputs. The closing processes group, specifically in the handover of project outputs, represents a critical aspect of project sustainability, because if there is no exploitation of project outputs, there is a waste of all resources allocated to the project. In this study, during the first sprints, there was a special focus on balancing or harmonizing social, environmental, and economic interests. A short-term orientation, without losing the long-term orientation, is clear in the development of the costing system in several short-time sprints. The sprint reviews, the sprint retrospective, and the periodical meetings allowed transparency and accountability. The handover allowed the responsibility for institutionalizing the costing system to be transferred to the organization, assuring the exploitation of the project results. Personal values and ethics were firmly deemed by the high and continuous involvement of key stakeholders during the costing system development. 


\section{Conclusions}

This paper attempted to answer the research question: is the agile project management approach suitable and useful to design and implement effective costing systems? bringing both theoretical and practical contributions. The use of an agile approach is proposed for improving the efficiency and effectiveness of the design and implementation of costing systems, making an important extension on the previously developed works. Moreover, this paper demonstrates how professionals can make easy use of Scrum in their organizations, in addition to giving an important contribution to cost management practice. This paper also shows the explanatory power of Scrum for the design and implementation of ABC systems. The context of the case study is also important, because of the relevance of effective costing systems in hospitals and the complexity and difficulties of such an environment for the development of costing systems and cost management activities. The case study developed in the imaging service of the hospital demonstrates that the methodology is practical and suitable.

Additionally, the proposed methodology incorporates a number of factors that can later facilitate the embedding of the costing system in the organization, namely by the highly involvement of stakeholders, the involvement of key stakeholders in the adaptation of the cost model and costing system to the organizational context, as well as the constant validation of the cost model and costing system increments during the sprint reviews. This key involvement of stakeholders, promoted by using the Scrum methodology, allowed stakeholders to easily converge opinions to a solution on the design and the implementation of the costing system. And this is vital to promote the institutionalization of the costing system in the organization. For instance, the high involvement and support of the administrative staff of the imaging service is vital for the institutionalization of the proposed model and related costing and cost management practices.

Nevertheless, like any methodology, it portrays a simplification of the reality and should be used with caution. For example, in this particular case, the burndown chart was not applied, although the Scrum Master and Development Team perceived the technique as useful. Additionally, by attending the level of maturity of the Development Team in agile project management approaches, the technique was perceived complex and not easy to use; therefore, it was not adopted. Nevertheless, it is important to note that if a project management technique is effectively embedded in the organization structure, it will be adopted more easily in the costing system project. As presented in this article, using an agile methodology allows to develop costing systems tailored to the organization from a cost-benefit point of view and a collaborative and iterative approach.

Finally, a detailed report on how the methodology was applied to the particular case study also sheds light on how organizations in general can make use of agile project management approaches to become more successful. In particular, in the hospital imaging service, it helped to increase stakeholder engagement regarding cost management, as well as to adapt cost management tools and costing systems to the organizational structure of the hospital (cost accounting techniques, type of resources, and information systems).

We must acknowledge the drawbacks of the research study, which mainly result from the decisions made concerning the methodological approach. The Scrum methodology for the design and implementation of costing systems was only evaluated in one case study and the research site has its particularities. Hence, results and findings cannot be generalized to other companies and industries, to other cost models, and to other agile project management practices. In this regard, future studies can induce multiple case studies and cross-check the conclusions among them, thereby increasing the generalizability of the results, as well as to extend its application to other cost model approaches, such as Time-driven ABC (TDABC) or others. Furthermore, the application of particular project management tools and techniques, such as agile earned value management, can also be studied. 
Author Contributions: The three authors collaborated to produce this paper. V.J., as the principal researcher, designed and conducted the research in the field; P.A. (costing systems) and G.F. (agile project management) provided guidance and support for the field work and the development of the model. The three authors contributed to the analysis and interpretation of the results. All authors have read and agreed to the published version of the manuscript.

Funding: This research is sponsored by FEDER funds through the program COMPETE-Programa Operacional Factores de Competitividade — and by national funds through the FCT-Fundação para a Ciência e a Tecnologia- under the project UIDB/00285/2020 and UIDB/00319/2020.

Conflicts of Interest: The authors declare no conflict of interest.

\section{References}

1. Lueg, R.; Storgaard, N. The adoption and implementation of Activity-based Costing: A systematic literature review. Int. J. Strateg. Manag. 2017, 17, 7-24. [CrossRef]

2. Berg, T.; Madsen, D.Ø. The historical evolution and popularity of activity-based thinking in management accounting. J. Account. Organ. Chang. 2020, 16, 401-425. [CrossRef]

3. Anderson, S.W.; Young, S.M. The impact of contextual and process factors on the evaluation of activity-based costing systems. Account. Organ. Soc. 1999, 24, 525-559. [CrossRef]

4. Allain, E.; Laurin, C. Explaining implementation difficulties associated with activity-based costing through system uses. J. Appl. Account. Res. 2018, 19, 181-198. [CrossRef]

5. Gosselin, M. A Review of Activity-Based Costing: Technique, Implementation, and Consequences. In Handbooks of Management Accounting Research; Elsevier: Amsterdam, The Netherlands, 2006; Volume 2, pp. 641-671. ISBN 9780080447544. [CrossRef]

6. Gosselin, M. The effect of strategy and organizational structure on the adoption and implementation of activity-based costing. Account. Organ. Soc. 1997, 22, 105-122. [CrossRef]

7. Shields, M.D. An empirical analysis of firms' implementation experiences with activity-based costing. J. Manag. Account. Res. 1995, 7, 148.

8. PMI. A Guide to the Project Management Body of Knowledge (PMBOK ${ }^{\circledR}$ Guide), 6th ed.; PMI: Newtown Square, PA, USA, 2017.

9. Too, E.G.; Weaver, P. The management of project management: A conceptual framework for project governance. Int. J. Proj. Manag. 2014, 32, 1382-1394. [CrossRef]

10. Joslin, R.; Müller, R. Relationships between a project management methodology and project success in different project governance contexts. Int. J. Proj. Manag. 2015, 33, 1377-1392. [CrossRef]

11. Badewi, A. The impact of project management (PM) and benefits management (BM) practices on project success: Towards developing a project benefits governance framework. Int. J. Proj. Manag. 2016, 34, 761-778. [CrossRef]

12. Liu, L.Y.J.; Pan, F. The implementation of Activity-Based Costing in China: An innovation action research approach. Br. Account. Rev. 2007, 39, 249-264. [CrossRef]

13. Eskerod, P.; Huemann, M.; Ringhofer, C. Stakeholder inclusiveness: Enriching project management with general stakeholder theory. Proj. Manag. J. 2015, 46, 42-53. [CrossRef]

14. Atkinson, R. Project management: Cost, time and quality, two best guesses and a phenomenon, its time to accept other success criteria. Int. J. Proj. Manag. 1999, 17, 337-342. [CrossRef]

15. Munns, A.K.; Bjeirmi, B.F. The role of project management in achieving project success. Int. J. Proj. Manag. 1996, 14, 81-87. [CrossRef]

16. Kolltveit, B.J.; Karlsen, J.T.; Grønhaug, K. Perspectives on project management. Int. J. Proj. Manag. 2007, 25, 3-9. [CrossRef]

17. Cooke-Davies, T. The "real" success factors on projects. Int. J. Proj. Manag. 2002, 20, 185-190. [CrossRef]

18. Klein, L.; Biesenthal, C.; Dehlin, E. Improvisation in project management: A praxeology. Int. J. Proj. Manag. 2015, 33, 267-277. [CrossRef]

19. Gaupin, G.; Knoepfel, H.; Koch, G.; Pannenbäcker, K.; Pérez-Polo, F.; Seabury, C. ICB: IPMA Competence Baseline; Version 3.0.; IPMA: Nijkerk, The Netherlands, 2006.

20. Ciric, D.; Lalic, B.; Gracanin, D.; Tasic, N.; Delic, M.; Medic, N. Agile vs. Traditional Approach in Project Management: Strategies, Challenges and Reasons to Introduce Agile. Procedia Manuf. 2019, 39, 1407-1414. [CrossRef] 
21. Fernandez, D.J.; Fernandez, J.D. Agile Project Management-Agilism Versus Traditional Approaches. J. Comput. Inf. Syst. 2008, 49, 10-17. [CrossRef]

22. Böhmer, A.I.; Beckmann, A.; Lindemann, U. Open innovation ecosystem-makerspaces within an agile innovation process. In Proceedings of the ISPIM Innovation Summit; ISPIM: Brisbane, Australia, 2015; pp. 1-11.

23. Wysocki, R.K. Effective Project Management: Traditional, Agile, Extreme, 7th ed.; John Wiley \& Sons: Hoboken, NJ, USA, 2014; ISBN 1118729161.

24. Cicmil, S.; Cooke-Davies, T.; Crawford, L.; Richardson, K. Exploring the Complexity of Projects: Implications of Complexity Theory for Project Management Practice; Project Management Institute: Newton Square, PA, USA, 2009; ISBN 1628251298.

25. Apaolaza, U.; Lizarralde, A. Managing Multiple Projects in Uncertain Contexts: A Case Study on the Application of a New Approach Based on the Critical Chain Method. Sustainability 2020, 12, 5999. [CrossRef]

26. Engwall, M. No project is an island: Linking projects to history and context. Res. Policy 2003, 32, 789-808. [CrossRef]

27. Toljaga-Nikolić, D.; Todorović, M.; Dobrota, M.; Obradović, T.; Obradović, V. Project management and sustainability: Playing trick or treat with the planet. Sustainability 2020, 12, 8619. [CrossRef]

28. Gilbert Silvius, A.J.; Kampinga, M.; Paniagua, S.; Mooi, H. Considering sustainability in project management decision making; An investigation using Q-methodology. Int. J. Proj. Manag. 2017, 35, 1133-1150. [CrossRef]

29. Armenia, S.; Dangelico, R.M.; Nonino, F.; Pompei, A. Sustainable project management: A conceptualization-oriented review and a framework proposal for future studies. Sustainability 2019, 11. [CrossRef]

30. Thomas, T.F. Motivating revisions of management accounting systems: An examination of organizational goals and accounting feedback. Account. Organ. Soc. 2016, 53, 1-16. [CrossRef]

31. Peffers, K.; Tuunanen, T.; Rothenberger, M.A.; Chatterjee, S. A Design Science Research Methodology for Information Systems Research. J. Manag. Inf. Syst. 2007, 24, 45-77. [CrossRef]

32. Jassem, S. Benefits of Switching from Activity-Based Costing to Resource Consumption Accounting: Evidence from a Power Generator Manufacturing Plant. Manag. Account. Rev. 2019, 18, 169-190. [CrossRef]

33. Tan, S.S.; Rutten, F.F.H.; Van Ineveld, B.M.; Redekop, W.K.; Hakkaart-Van Roijen, L. Comparing methodologies for the cost estimation of hospital services. Eur. J. Heal. Econ. 2009, 10, 39-45. [CrossRef]

34. Ax, C.; Greve, J. Adoption of management accounting innovations: Organizational culture compatibility and perceived outcomes. Manag. Account. Res. 2017, 34, 59-74. [CrossRef]

35. Malmi, T. Towards explaining activity-based costing failure: Accounting and control in a decentralized organization. Manag. Account. Res. 1997, 8, 459-480. [CrossRef]

36. Al-Dhubaibi, A.A.S. Optimizing the value of activity based costing system: The role of successful implementation. Manag. Sci. Lett. 2021, 11, 179-186. [CrossRef]

37. Fei, Z.Y.; Isa, C.R. Factors Influencing Activity-Based Costing Success: A Research Framework. Int. J. Trade Econ. Financ. 2010, 1, 144-150. [CrossRef]

38. Journal, J.; Collection, I.; Kennedy, T.; Affleck-Graves, J. The impact of activity-based costing techniques on firm performance. J. Manag. Account. Res. 2001, 13, 19-45. [CrossRef]

39. Fowler, M.; Highsmith, J. The agile manifesto. Softw. Dev. 2001, 9, 28-35.

40. Cubric, M. An agile method for teaching agile in business schools. Int. J. Manag. Educ. 2013, 11, 119-131. [CrossRef]

41. Boehm, B.; Turner, R. Management Challenges to Implementing Agile Processes in Traditional Development Organizations. IEEE Softw. 2005, 22, 30-39. [CrossRef]

42. Cooper, R.G.; Sommer, A.F. The Agile-Stage-Gate Hybrid Model: A Promising New Approach and a New Research Opportunity. J. Prod. Innov. Manag. 2016, 33, 513-526. [CrossRef]

43. Schwaber, K. Scrum development process. In Business Object Design and Implementation; Springer: Berlin/Heidelberg, Germany, 1997; pp. 117-134. ISBN 3540760962.

44. Beck, K. Extreme Programming Explained: Embrace Change; Professional, A., Ed.; Addison-Wesley Professional: Boston, MA, USA, 1999; ISBN 0201616416.

45. Ebert, C.; Abrahamsson, P.; Oza, N. Lean software development. IEEE Softw. 2012, 29, 22-25. [CrossRef]

46. Meso, P.; Jain, R. Agile Software Development: Adaptive Systems Principles and Best Practices. Inf. Syst. Manag. 2006, 0530, 19-30. [CrossRef] 
47. Cockburn, A. Crystal Clear: A Human-Powered Methodology for Small Teams; Pearson Education: London, UK, 2004; ISBN 0132702495.

48. Streule, T.; Miserini, N.; Bartlomé, O.; Klippel, M.; De Soto, B.G. Implementation of Scrum in the Construction Industry. Procedia Eng. 2016, 164, 269-276. [CrossRef]

49. Cervone, H.F. Understanding agile project management methods using Scrum. OCLC Syst. Serv. Int. Digit. Libr. Perspect. 2011, 27, 18-22. [CrossRef]

50. Takeuchi, H.; Nonaka, I. The new new product development game. J. Prod. Innov. Manag. 1986, 3, 205-206. [CrossRef]

51. Chan, F.K.Y.; Thong, J.Y.L. Acceptance of agile methodologies: A critical review and conceptual framework. Decis. Support Syst. 2009, 46, 803-814. [CrossRef]

52. Satpathy, T. A Guide to the Scrum Body of Knowledge (SBOK ${ }^{T M}$ Guide); Scrumstudy ${ }^{\mathrm{TM}}$, a Brand VMEdu, Inc.: Phoenix, AZ, USA, 2016.

53. Santos, N.; Fernandes, J.M.; Carvalho, M.S.; Silva, P.V.; Fernandes, F.A.; Rebelo, M.P.; Barbosa, D.; Maia, P.; Couto, M.; Machado, R.J. Using scrum together with UML models: A collaborative university-industry R\&D software project. In Proceedings of the International Conference on Computational Science and Its Applications, Beijing, China, 4-7 July 2016; Springer: Cham, Switzerland, 2016; pp. 480-495.

54. Hidalgo, E.S. Adapting the scrum framework for agile project management in science: Case study of a distributed research initiative. Heliyon 2019, 5, e01447. [CrossRef] [PubMed]

55. Torrecilla-Salinas, C.J.; Sedeño, J.; Escalona, M.J.; Mejías, M. Estimating, planning and managing Agile Web development projects under a value-based perspective. Inf. Softw. Technol. 2015, 61, 124-144. [CrossRef]

56. Baskerville, R.L.; Kaul, M.; Storey, V.C. Genres of inquiry in design-science research: Justification and evaluation of knowledge production. Mis Q. 2015, 39, 541-564. [CrossRef]

57. Hevner, A.R.; March, S.T.; Park, J.; Ram, S. Design science in information systems research. Mis Q. 2004, 28, 75-105. [CrossRef]

58. March, S.T.; Smith, G.F. Design and natural science research on information technology. Decis. Support Syst. 1995, 15, 251-266. [CrossRef]

59. Peffers, K.; Tuunanen, T.; Niehaves, B. Design science research genres: Introduction to the special issue on exemplars and criteria for applicable design science research. Eur. J. Inf. Syst. 2018, 27, 129-139. [CrossRef]

60. Larsson, P. Reflexive methodology: New vistas for qualitative research (second edition), by Mats Alvesson and Kaj Sköldberg. Eur. J. Psychother. Couns. 2010, 12, 89-91. [CrossRef]

61. Worline, M. Organizational Ethnography: Studying the Complexities of Everyday Life by Sierk Ybema, Dvora Yanow, Harry Wels, and Frans Kamsteeg. Int. Public Manag. J. 2012, 15, 235-238. [CrossRef]

62. Saunders, M.; Lewis, P.; Thornhill, A. Research methods for business students (Seventh). Nueva York Pearson Educ. 2016.

63. Baker, L. Observation: A complex research method. Libr. Trends 2006, 55, 171-189. [CrossRef]

64. Schwaber, K.; Sutherland, J. The Scrum Guide-The Definitive Guide to Scrum: The Rules of the Game; Ken Schwaber and Jeff Sutherland: Cambrige, MA, USA, 2017.

65. Zhang, Y.F.; Hoque, Z.; Isa, C.R. The effects of organizational culture and structure on the success of activity-based costing implementation. Adv. Manag. Account. 2015, 25, 229-257. [CrossRef]

66. Fernandes, G.; Ward, S.; Araújo, M. Developing a framework for embedding useful project management improvement initiatives in organizations. Proj. Manag. J. 2014, 45, 81-108. [CrossRef]

67. Borges, C.M.; Ramalho, R.; Bajanca, M.; Oliveira, T.; Major, M.J.; Diz, P.; Rodrigues, V. Implementação de um sistema de custeio por actividades nos hospitais do SNS. Rev. Port. Saúde Pública 2010, 9, 141-160.

68. Fernandes, G.; Ward, S.; Araújo, M. Improving and embedding project management practice in organisations-A qualitative study. Int. J. Proj. Manag. 2015, 33, 1052-1067. [CrossRef]

69. Anderson, S.W.; Hesford, J.W.; Young, S.M. Factors influencing the performance of activity based costing teams: A field study of ABC model development time in the automobile industry. Account. Organ. Soc. 2002, 27, 195-211. [CrossRef]

70. Himme, A. Critical success factors of strategic cost reduction. J. Manag. Control 2012, 23, 183-210. [CrossRef]

71. Žužek, T.; Gosar, Ž.; Kušar, J.; Berlec, T. Adopting agile project management practices in non-software SMEs: A case study of a slovenian medium-sized manufacturing company. Sustainability 2020, 12, 9245. [CrossRef]

72. Van Der Beek, D.; Schraagen, J.M. ADAPTER: Analysing and developing adaptability and performance in teams to enhance resilience. Reliab. Eng. Syst. Saf. 2015, 141, 33-44. [CrossRef] 
73. Gonzalez, M.; Nachtmann, H.; Pohl, E. Time-driven activity-based costing for health care provider supply chains. Eng. Econ. 2017, 62, 161-179. [CrossRef]

74. Calvi, K.; Chung, S.H.; Havens, R.; Economou, M.; Kulkarni, R. Simulation study integrated with activity-based costing for an electronic device re-manufacturing system. Int. J. Adv. Manuf. Technol. 2019, 127-140. [CrossRef]

75. Silvius, G.; SChIPPER, R.O.N.; Planko, J. Sustainability in Project Management; Gower Publishing, Ltd.: Aldershot, UK, 2012; ISBN 140943169X.

Publisher's Note: MDPI stays neutral with regard to jurisdictional claims in published maps and institutional affiliations.

(C) 2020 by the authors. Licensee MDPI, Basel, Switzerland. This article is an open access article distributed under the terms and conditions of the Creative Commons Attribution (CC BY) license (http://creativecommons.org/licenses/by/4.0/). 